\title{
INDIRECT SELECTION FOR ENVIRONMENTAL SENSITIVITY IN NICOTIANA RUSTICA
}

\author{
M. K. S. AL-BANNA AND J. L. JINKS \\ Department of Genetics, University of Birmingham, Birmingham B15 2TT
}

Received 31.v.83

\begin{abstract}
SUMMARY
Indirect selection for high and low sensitivity to macroenvironmental differences for final height $(\mathrm{FH})$ has been practised among $\mathrm{F}_{2}$ individuals of the cross of varieties 2 and 12 of Nicotiana rustica using a selection index (R7) proposed by Boughey and Jinks (1978), which is the proportion of FH achieved by the middle of the growing season. The $\mathrm{F}_{3}$ progenies of the selections and of unselected controls were assessed in the range of environments in which the selection index was both measured and originally validated ( 2 sowing dates $\times 2$ planting densities at the University site), as well as in a similar set of environments at the poorer Avoncroft site. A correlation analysis combined with a significant response to selection confirms that pattern of growth as summarised by $\mathrm{R7}$ is a major determinant of environmental sensitivity of $\mathrm{FH}$ to the environmental treatments at the University site and that it has a high repeatability and heritability. The same analysis and the absence of a response to selection at the Avoncroft site show that the usefulness of the selection index is limited to the University site.
\end{abstract}

\section{INTRODUCTION}

Differences in environmental sensitivity among highly inbred families of Nicotiana rustica are related to differences in their patterns of growth (Perkins and Jinks, 1968; Perkins, 1974; Boughey and Jinks, 1978; Boughey, Jinks, Coombs and Shufflebotham, 1978). In particular, pattern of growth, as summarised by the proportion of the final plant height achieved by the middle of the growing season (R7) and the quadratic component of the growth curve, is highly negatively correlated with estimates of the environmental sensitivity $\left(\sigma_{b}\right)$ of final height to planting density and sowing date at the University site in random samples of recombinant inbred lines derived from the cross of varieties 2 and 12 (Boughey and Jinks, 1978; Boughey et al., 1978). Boughey and Jinks, therefore, suggested that indirect selection for environmental sensitivity of final height could be practised by selecting for the ratio $\mathrm{R} 7$ and that this should avoid the difficulties previously encountered in direct selection (Brumpton, Boughey and Jinks, 1977; Jinks, Jayasekara and Boughey, 1977).

We shall now examine whether the relationship between $\mathrm{R} 7$ and environmental sensitivity of final height extends to the segregating generation of a cross, we shall estimate its heritability in these generations and test its value and general validity as a selection index for environmental sensitivity.

\section{MATERIAls AND METHOD}

$98 \mathrm{~F}_{3}$ families were produced by self-pollinating 98 randomly chosen plants of the $F_{2}$ of the cross of varieties 2 and 12 of $N$. rustica raised in a completely randomised experiment at the University site in 1978. The $F_{2}$ 
plants were scored individually for height seven weeks after planting in the field $(\mathrm{H} 7)$ and final height $(\mathrm{FH})$ which are the components of $\mathrm{R7}=\mathrm{H} 7 / \mathrm{FH}$. Using R7 as an indirect selection criterion for environmental sensitivity of final height, a low sensitivity selection was initiated by choosing the $4 F_{2}$ plants with the highest $R 7$ values and a high sensitivity selection was initiated by choosing the $4 F_{2}$ plants with the lowest $R 7$ values.

Ten progeny of each of the $98 \mathrm{~F}_{3}$ families, which include the 8 families of the high and low selections, along with 10 replicate plants of the parental varieties, 2 and 12, and their reciprocal $F_{1}$ 's and 40 progeny of each of the reciprocal $F_{2}$ 's were raised in a completely randomised design in each of 8 environments in 1980. The environments consisted of two planting densities (high and normal) on each of two sowing dates (four weeks apart) at each of two sites, University and Avoncroft. The University site is the one in which the selection index R7 was measured and the four environmental treatments at this site were the environments in which the relationship between R7 and envrionmental sensitivity for final height had previously been observed.

The Avoncroft site is a poorer environment than the University. At Avoncroft, varieties 2 and 12 and derivatives of the cross between them grow more slowly and on average are 10 to 15 per cent smaller at the end of the season. Larger genotypes are reduced more than smaller ones and as a result the range of plant heights at the end of the season is 12 to 25 per cent less than on the University site. Similarly the range of environmental sensitivities to the four environmental treatments is correspondingly reduced on the Avoncroft site.

Plant height seven weeks after planting ( $\mathrm{H} 7)$ and at the end of the growing season $(\mathrm{FH})$ were scored on each of the 8800 plants raised in total in the 8 environments.

\section{Results}

\section{(i) Measures of environmental sensitivity}

Two measures of environmental sensitivity have been used. The first is the square root of the between environments component of variation $\left(\sigma_{b}\right)$ (Brumpton et al., 1977). This was estimated for each of the 104 families by carrying out one way analyses of variance for the four environmental treatments at each site. The second is the regression coefficient $(1+b)$ of the linear regression of the phenotypic mean of each family in each of the four environments at each site on their additive environmental values $\left(e_{j}\right.$ 's) (Perkins and Jinks, 1968). The linear regression coefficient was estimated for each of the 104 families using the mean of all families in each environment as its environmental value. Where there is no significant non-linear component these coefficients measure the relative sensitivities of the 104 families otherwise they measure the relative linear component of these sensitivities.

\section{(ii) Selection index and environmental sensitivity}

The correlations between the $R 7$ values of the $98 F_{2}$ parents and the estimate of the environmental sensitivities of $\mathrm{FH}$ in their $\mathrm{F}_{3}$ families in the four environmental treatments at the University site are given in table 1. 


\section{TABLE 1}

The correlation between the selection index $(R 7)$ in $F_{2}$ parents and environmental sensitivities $\left(\sigma_{\mathrm{b}}\right.$ and $\left.1+\mathrm{b}\right)$ of. their $F_{3}$ progenies to environmental treatments at the University and Avoncroft sites

\begin{tabular}{ccc}
\hline Site & $\mathrm{R} 7 / \sigma_{b}$ & $R 7 /(1+b)$ \\
\hline University & $-0.25(P=0.01)$ & $-0.29(P=0.004)$ \\
Avoncroft & $0.003(P=0.98)$ & $0.11(P=0.27)$ \\
\hline
\end{tabular}

Whether sensitivity is measured by $\sigma_{b}$ or $(1+b)$ the correlation is significant and takes a similar negative value. Both, however, are smaller than the correlation of -0.42 reported by Boughey and Jinks (1978) and Boughey et al., (1978). This, however, is probably no more than a reflection of the greater sampling error of the $\mathrm{R} 7$ values in the present experiment where they are based on single $F_{2}$ plants compared with the earlier experiment where they were based on the means of eight replicates of highly inbred families.

\section{(iii) Heritability of the selection index}

To be effective as a selection index $\mathrm{R} 7$ must have a high correlation between parent and progeny mean. This correlation for the $98 \mathrm{~F}_{2}$ parents and their $98 \mathrm{~F}_{3}$ families averaged over the four environmental treatments is $0.76(P=0.001)$ at both the University site and at the Avoncroft site. It compares favourably with the estimate of 0.54 for the narrow heritability of the index (Boughey et al., 1978).

\section{(iv) Selections}

The relationship between $\mathrm{R} 7$ and environmental sensitivity for $\mathrm{FH}$ and the high heritability for R7 reported by Boughey and Jinks and Boughey et al., (loc.cit.) appear to apply to the early segregating generations of the cross of varieties 2 and 12 . It should, therefore, be possible to select for sensitivity in the $F_{2}$ using $R 7$. The mean $R 7$ of the $98 \mathrm{~F}_{2}$ plants raised at the University site in 1978 and of the eight plants chosen from them to initiate the high and low selections are given in table 2 . Alongside are given the estimates of the environmental sensitivities $\left(\sigma_{b}\right.$ and $\left.1+b\right)$ to the four

TABLE 2

The mean $R 7$ values of the $F_{2}$ parents of the control and high and low selections and the mean environmental sensitivities $\left(\sigma_{\mathrm{b}}\right.$ and $\left.1+\mathrm{b}\right)$ of their $F_{3}$ progenies to environmental treatments at the University and Avoncroft sites

\begin{tabular}{lcrrrr}
\hline & & \multicolumn{4}{c}{$F_{3}$ progenies $(1980)$} \\
Material & $\mathrm{F}_{2}$ parents $(1978)$ & \multicolumn{2}{c}{ University } & \multicolumn{2}{c}{ Avoncroft } \\
& $\mathrm{R} 7$ & $\sigma_{b}$ & $(1+b)$ & \multicolumn{1}{c}{$\sigma_{b}$} & $(1+b)$ \\
\hline Control & 0.65 & 3.91 & 1.08 & 3.89 & 1.03 \\
High selection & 0.29 & 6.40 & 0.94 & -1.84 & 0.39 \\
Low selection & 0.89 & 1.38 & 0.14 & 0.36 & 0.77 \\
\hline
\end{tabular}


environmental treatments at the University site for the $F_{3}$ control and the high and low selections. For $\sigma_{b}$ the selections show a marked response in the direction expected both relative to one another and to the control. For the alternative measure of environmental sensitivity $(1+b)$ the selections also show a marked response in the expected direction relative to one another but the high selection is marginally lower than the control. This suggests that part of the increase in sensitivity in the high selection is non-linear.

\section{(v) Environmental specificity}

The $F_{3}$ families of the high and low selections and control were also raised in the same combination of environmental treatments at a contrasting site, Avoncroft, in order to examine the generality of the findings. The correlations between $F_{2}$ parent and $F_{3}$ progeny family mean for R7 had the same high value of 0.76 at Avoncroft as at the University site (section iii). On the other hand, the correlations between $R 7$ of the $F_{2}$ parents and the environmental sensitivity estimates of their $F_{3}$ progenies at the Avoncroft site were much smaller than at the University site and no longer either negative or significant (see table 1). Not surprisingly, therefore, the high and low selections showed no response when assessed at the Avoncroft site although the mean estimates of environmental sensitivity $\left(\sigma_{b}\right.$ and $\left.1+b\right)$ for the controls did not differ from those at the University site (table 2). It is clear, therefore, that the selection index R7 measured on the University site and whose potential value was first recognised at the University site has been effective only at that site.

\section{(vi) The efficiency of indirect selection}

Since all 98 of the random sample of $F_{3}$ families were assessed in all environments it is possible to investigate how successful the indirect selection has been in obtaining high and low selections for environmental sensitivity. If the indirect selection had been 100 per cent successful, $F_{2}$ parents of the four most sensitive and four least sensitive of the $98 \mathrm{~F}_{3}$ families would have been chosen. The $F_{3}$ families of these hypothetical perfect high and low selections can be identified among the 98 raised. The relative success of the actual indirect selections can then be measured as the ratio of the differences in environmental sensitivity between the actual and hypothetical high and low selections. For example, the difference between the environmental sensitivities of the indirect high and low selections at the University site measured as $\sigma_{b}$ is 5.02 (see table 2), the difference between the corresponding hypothetical selections at this site is $24 \cdot 19$. Thus the indirect selection achieved 21 per cent of the maximum possible response from the same $98 \mathrm{~F}_{2}$ parents. For the alternative measure of environmental sensitivity $(1+b)$, the corresponding success rate is 20 per cent. Bearing in mind that the correlation between the selection index in $F_{2}$ parents and the environmental sensitivity of their $\mathrm{F}_{3}$ progenies as measured by $\sigma_{b}$ and $(1+b)$ is only $-0 \cdot 25$ and $-0 \cdot 29$, respectively (table 1 ), a 20 per cent success rate is remarkably good. 


\section{Conclusions}

The results (table 2) show that environmental sensitivity can be selected indirectly using an index which can be measured on single plants raised in a single environment. The selections made on the basis of the index measured at the University site were successful when assessed at that site but not when assessed at the poorer Avoncroft site. This suggests that the differences in environmental sensitivity which are generated by genotype $\times$ treatment interactions within each site differ between the University and Avoncroft sites because of genotype $\times$ site interactions. It remains to be seen whether selections based on the index measured at another site will be successful at that site and only at that site.

Acknowledgements. We gratefully acknowledge the receipt of a grant from the University of Baghdad, Iraq, during the course of this work. We also thank Dr H. S. Pooni for advice and assistance.

\section{REFERENCES}

BOUGHEY, H. AND JINKS, J. L. 1978. Joint selection for both extremes of men performance and of sensitivity to a macro-environmental variable. III. The determinants of sensitivity. Heredity, 40, 363-369.

BOUGHEY, H., JINKS, J. L., COOMBES, D. AND SHUFFLEBOTHAM, W. 1978. Joint selection for both extremes of mean performance and of sensitivity to a macro-environmental variable. IV. Growth pattern and sensitivity. Heredity, 41, 175-183.

BRUMPTON, R. J., BOUGHEY, H. AND JINKS, J. L. 1977. Joint Selection for both extremes of mean performance and of sensitivity to a macro-evironmental variable. I. Family selection. Heredity, 38, 219-226.

JINKS, J. L., JAYASEKARA, N. E. M. AND BOUGHEY, H. 1977. Joint selection for both extremes of mean performance and of sensitivity to a macro-environmental variable. II. Single seed descent. Heredity, 39, 345-355.

PERKINS, J. M. 1974. Orthogonal and principal components analysis of genotype-environmental interactions for multiple metrical traits. Heredity, 32, 189-209.

PERKINS, J. M. AND JINKS, J. L. 1968. Environmental and genotype-environmental components of variability. III. Multiple lines and crosses. Heredity, 23, 339-356. 